TITLE:

\title{
Morphotype distribution of the sea anemone Diadumene lineata in \\ Tanabe Bay, Wakayama: a comparison with Uchida (1936) after 80 years
}

\author{
AUTHOR(S): \\ Ryan, Will H.; Kubota, Shin
}

\section{CITATION:}

Ryan, Will H. ... [et all. Morphotype distribution of the sea anemone Diadumene lineata in Tanabe Bay, Wakayama: a comparison with Uchida (1936) after 80 years. Publications of the Seto Marine Biological Laboratory 2016, 44: 1-6

ISSUE DATE:

2016-03-04

URL:

http://hdl.handle.net/2433/209001

RIGHT: 
Publ. Seto Mar. Biol. Lab., 44: 1-6, published online, 2016; published in print, 2018.

\title{
Morphotype distribution of the sea anemone Diadumene lineata in Tanabe Bay, Wakayama: a comparison with Uchida (1936) after 80 years
}

\author{
WILL H. RYAN ${ }^{*}$ AND SHIN KUBOTA ${ }^{* *}$ \\ *Florida State University, Department of Biological Science, Tallahassee FL, USA \\ ${ }^{* *}$ Seto Marine Biological Laboratory, Kyoto University, Japan \\ "E-mail: wryan@bio.fsu.edu
}

\begin{abstract}
The intertidal sea anemone Diadumene lineata is a common inhabitant of East Asian shores, including most of Japan. It has long been interesting to researchers because populations show high levels of morphotypic diversity and a variety of reproductive strategies, including both asexual and sexual modes. We compared the current distribution of color morphs around Tanabe Bay, Wakayama, Japan with a historical survey of the region from 1936 and found that the population is still dominated by the same morphotype although all four morphotypes are present in the region. Additionally we found that distribution of body size and morphotype differed among sites within the region and that these populations are marked by a high level of reproductive diversity.
\end{abstract}

Keywords: Sea anemone, historical comparison, Tanabe Bay, asexual reproduction

\section{Introduction}

Diadumene lineata (Verrill, 1869) is a small, intertidal sea anemone common on all Japanese shores where an appropriate habitat is found. It is well known for its ability to tolerate variable temperatures (Miyawaki, 1952), salinities (Shick, 1976), and food availability (Minassian, 1979) and is also known for its variable reproductive habits and morphology (Uchida, 1932; Chia, 1976). Despite being a common and familiar inhabitant of the Japanese intertidal, Uchida's works $(1932,1936)$ remain some of the few descriptions of the natural occurrence and activity of this species in Japan. Because this species is now globally distributed, there is much interest in understanding the morphological and reproductive variation present in East Asia, as it is assumed to be the region of native origin (Uchida, 1932; Stephenson, 1935), however the original native range is unknown. Here we compare the current distribution of size, color morphotype, sex, reproductive state and evidence of asexual mode at three sites near the Seto Marine Biological Laboratory, Kyoto University, with the historical data from Uchida (1936) on the distribution of color morphotype from the same region.

\section{Materials and Methods}

\section{Site descriptions}

Because the exact sites used by Uchida (1936) are unknown, three intertidal sites were chosen around the perimeter of Tanabe Bay, Wakayama to maximize geographic coverage and habitat diversity. All three were strongly influenced by freshwater inputs and were well protected from wave action, though the substrate and 
community varied among the three locations. At all sites, anemones only occur in the upper intertidal, well above the average low tide height. At Seto Harbor ("Harbor", GPS: $33.689^{\circ} \mathrm{N}, 135.344^{\circ} \mathrm{E}$ ), a very sheltered site, Diadumene lineata occurs abundantly in cracks in the cement boat ramp alongside small mussels and barnacles. At the Uchinoura mudflat ("Mudflat", GPS: $33.693^{\circ} \mathrm{N}, 135.388^{\circ} \mathrm{E}$ ) the species occurs abundantly, but patchily in the oysters exposed at low tide. At the mouth of Aizu river ("Exposed", GPS: $33.729^{\circ} \mathrm{N}$, $135.371^{\circ} \mathrm{E}$ ), the species occurs in low density on the underside of rocks in shallow rock pools formed far inland of the surf line. At each site, salinity was measured with a refractometer at the time of collection and was shown to be 29,22 and 20 , respectively.

\section{Collecting protocol}

Between June 30 and July 3, 2015, each site was visited during one low tide cycle. Researchers searched haphazardly until a patch was located, then all of the D. lineata in an area were collected. At each site, the area searched was no greater than approximately 20 x 20 meters. Anemones were collected by hand, using forceps to gently detach the pedal disk from the substrate, and were returned to the lab for morphological diagnosis. All anemones were processed live within 48 hours of collection.

The details of Uchida's (1936) collection methods are not given in the paper, so may reflect a larger searched area or collections amassed over a longer time period.

\section{Diagnosing morphologies}

In the laboratory, each anemone was photographed and inspected under a dissecting microscope. Based on its general color pattern, each was assigned to one of Uchida's (1932) four morphological categories (Fig. 1). While these categories do not account for all of the variation seen within types, it is a useful criterion in that intermediate morphologies between the types are not generally found (Uchida, 1932, 1936; personal observation). For type I individuals, the number of vertical, orange stripes was counted and the presence or absence of a fission scar was noted.
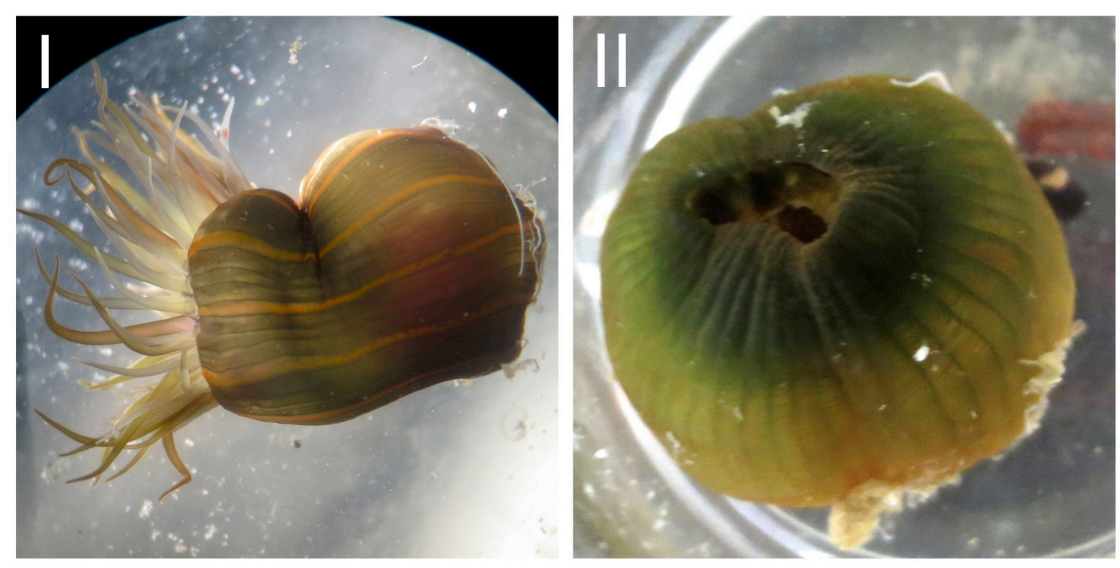

Figure 1. Photographic examples of each of Uchida's (1936) morphotypes. Individuals I, II and IV collected at Tanabe Bay. Individual III found near Misaki Marine Biological Station. Note the magenta colored eggs visible through the body wall in individual
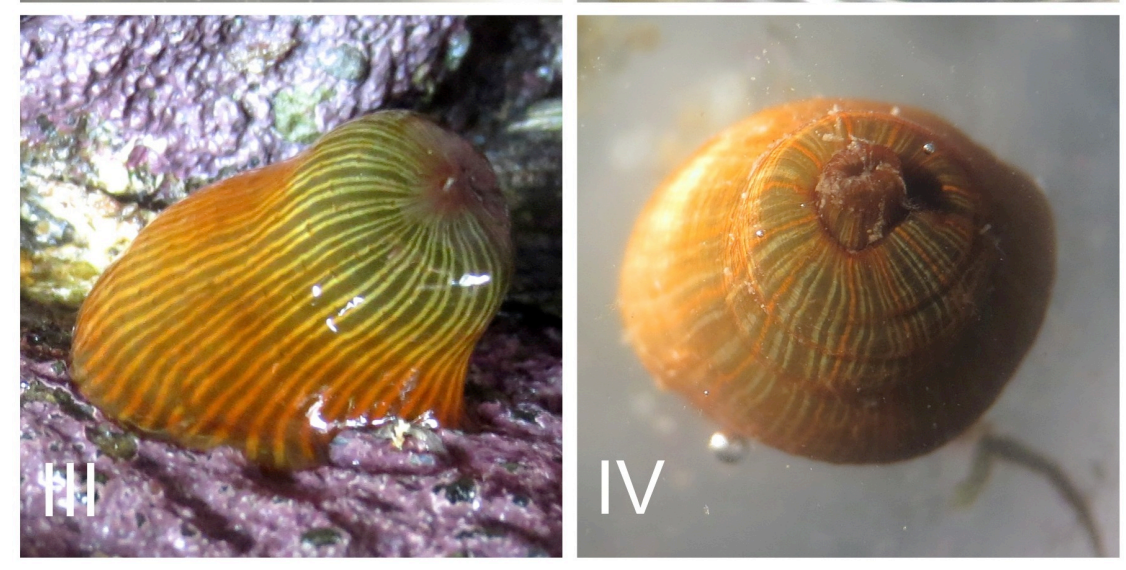
I. 
After binary fission, individuals generally show an area of discoloration and/or irregular patterning that arises at the site of fission. This mark generally persists for weeks to months (personal observation) and is a reliable indicator of recent fission events. Rapidly dividing clones may show more than one such mark on an individual. Individuals undergoing pedal laceration, however, do not usually leave such marks.

Pedal diameter for each individual was measured from the photographs using Image $\mathbf{J}$ analysis software (NIH, Bethesda MD).

\section{Diagnosing sex}

Diadumene lineata is known to be dioecious (Fukui, 1995), thus the sex of an individual can be determined when gametes are present. To assess the sex of each individual, each was dissected live with fine cuticle scissors under the dissecting microscope and scored as having eggs, sperm or no gametes present. Anemones were anesthetized for 20 minutes prior to dissection by soaking them in a 7\% solution of magnesium chloride in seawater. This prevents muscle contractions and the production of mucous during dissection, allowing a clear view of the mesentery to assess the presence of gonadal tissue. All statistical analyses were done using $\mathrm{R}$ (V 3.1.2 www.R-project.org).

\section{Results}

All four of Uchida's morphotypes were observed, though not all at every site. Similarly to Uchida, the type I individuals comprised the great majority of individuals (Table 1). When the data are pooled within years, across sites, there is a significant difference in the distribution of morphotypes $(\mathrm{G} 2=42.34, \mathrm{df}=3, \mathrm{p}<0.0001$, goodness of fit test) between years, although the specifics of this comparison are not useful to interpret. Also interesting is that the three sites measured in the current sample differ from each other, both in morphological distribution ( $\mathrm{G} 2=18.19, \mathrm{df}=6, \mathrm{P}=0.006$, Table 1$)$ and in average body size (pedal diameter, $\mathrm{F}=18.02, \mathrm{df}=2$, $\mathrm{P}<0.0001$, Fig. 2). Individuals at the Mudflat site had significantly larger pedal diameters than the other two sites (distinguished with Tukey's HSD post hoc analysis). For type I individuals, the distribution of stripe number is similar in shape to that observed by Uchida, though is shifted toward fewer stripes, with the median number being 10 compared to Uchida's 12 . There were also fewer Type I individuals with many stripes in the current sample, although that may be attributed to categorical confusion by Uchida in assigning type III individuals with irregular patterns, since the category is circularly defined by stripe number.

Table 1. Count of individuals assigned to each morphological type by habitat and sample year. Percentage of total population at each site displayed in parentheses.

\begin{tabular}{ccc|ccc} 
& \multicolumn{2}{c|}{ Uchida (1936) } & \multicolumn{4}{|c}{ Ryan and Kubota (2015) } \\
Morphotype & Exposed & Protected & $\begin{array}{c}\text { (Seto) } \\
\text { Harbor }\end{array}$ & $\begin{array}{c}\text { (Aizu River) } \\
\text { Exposed }\end{array}$ & $\begin{array}{c}\text { (Uchinoura) } \\
\text { Mudflat }\end{array}$ \\
\hline I & $292(55 \%)$ & $410(94)$ & $32(82)$ & $20(80)$ & $30(79)$ \\
II & $173(33)$ & $23(5)$ & 0 & $4(16)$ & 0 \\
III & $38(7)$ & $1(0)$ & 0 & 0 & $2(5)$ \\
IV & $29(5)$ & $1(0)$ & $7(18)$ & $1(4)$ & $6(16)$
\end{tabular}




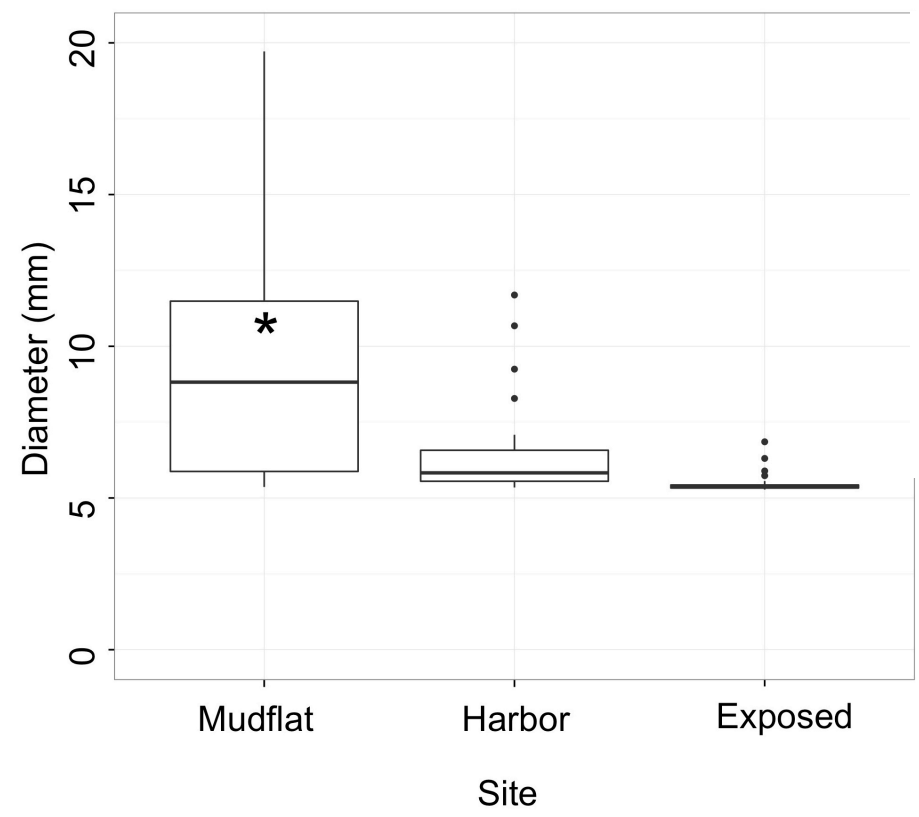

Figure 2. Mean basal diameter (mm) of individuals collected at each site. Boxes represent the 1st and 3rd quartile diameter measured at each site and 'whiskers' represent the distance to the most extreme value, except in the case of statistical outlier. At those sites, the most extreme values are represented by dots. Asterisk indicates that Mudflat individuals are, on average, significantly larger than those at the other two sites.

Of the 22 individuals that had gametes and could be reliably assigned to a sex, the ratio of males to females did not differ significantly from $1: 1(\mathrm{G}=0.73, \mathrm{df}=1, \mathrm{p}=0.392)$. Of the 50 individuals dissected, $56 \%$ were sterile (Table 2A). Sterile individuals tend to be the smaller individuals, agreeing with Uchida's observations, although it should be noted that small individuals should not be conflated with 'young' individuals because small size can be caused by asexual reproduction. The presence of gametes was significantly associated with morphotype $(\mathrm{G}=14.01, \mathrm{df}=3, \mathrm{p}=0.003)$, with type IV individuals having gametes more often than expected and type I individuals having them less often. However, interpretation of this result is complicated by type IV individuals being larger on average than the type I individuals. Interestingly, the greatest difference among sites seemed to be in the degree to which populations are structured by binary fission. In the 85 individuals examined between the harbor site and the mudflat site, zero individuals showed characteristic scar markings or irregular patterning associated with binary fission. In contrast, $60 \%$ of individuals from the exposed site showed such markings (Table $2 \mathrm{~B}$ ). The presence of scars was not significantly associated with morphotype (G $=5.47, \mathrm{df}=3, \mathrm{p}=0.14$ ), although as with all analysis, the low number of individuals of types II and III limit the power to detect such associations.

\begin{tabular}{|c|c|c|c|}
\hline $\begin{array}{c}\text { Gametes } \\
\text { present }\end{array}$ & Harbor & Exposed & Mudflat \\
\hline Eggs & $2(18 \%)$ & $1(8)$ & $10(37)$ \\
\hline Sperm & $5(45)$ & 0 & $4(15)$ \\
\hline Sterile & $4(36)$ & $11(92)$ & $13(48)$ \\
\hline \multicolumn{4}{|l|}{ B. } \\
\hline $\begin{array}{l}\text { Fission sc } \\
\text { presen }\end{array}$ & Harbor & Exposed & Mudflat \\
\hline Yes & 0 & $15(60)$ & 0 \\
\hline No & $45(100)$ & $10(40)$ & $40(100)$ \\
\hline
\end{tabular}

Table 2. Distribution of reproductive features noted in 2015, including both Sexual (A) and Asexual (B) features. Individuals that were too damaged or otherwise unable to be assessed were excluded from the sample. Percentage of total population displayed in parentheses. 


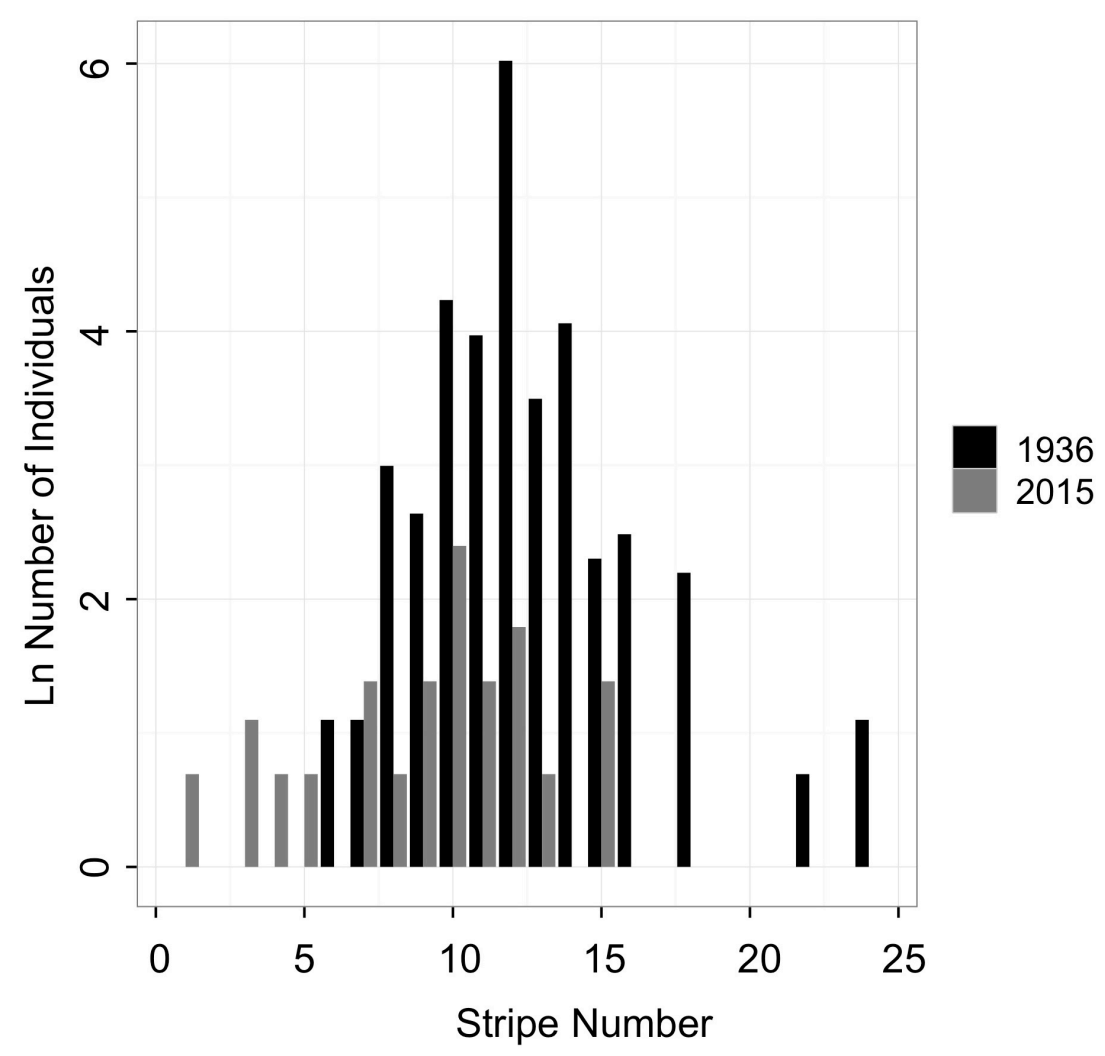

Figure 3. Distribution of stripe number for all type I individuals, combined across sites. Black bars redrawn from Uchida (1936). Grey bars indicates samples taken in 2015. Not all individuals that could be confidently assigned as type I could have their stripe number counted due to damage during collection. Note that the vertical axis is on a $\log$ scale to facilitate comparison between unequal sample sizes between years.

\section{Discussion}

Uchida's (1932) primary observations about the population of Diadumene lineata at Shirahama, Wakayama, remains true after 80 years. The population is still overwhelming dominated by type I individuals who mostly show between 10-14 orange stripes in a regular pattern. To such a result we have added observations that body size and morphological composition vary among sites, even within the region, that individuals in this region appear to undergo both sexual and asexual reproduction and that the sex ratio is not distinguishably skewed at the scale that we measured, despite the likely contribution of clonal reproduction to the spatial clumping of genotypes. One novel observation is the apparent abundance of pedal laceration as a form of asexual reproduction not previously documented at this site in English language literature. Many of the larger individuals with regular stripe patterns were surrounded by a halo of minute individuals, consistent with observed patterns of pedal laceration in other anemones (Metridium marginata; Hammat, 1906) and in this anemone but from a different location (Diadumene lineata from Miyagi Prefecture; Atoda, 1973). It appears that Shirahama may be a location of exceptional diversity for reproductive strategies in Diadumene lineata.

\section{Acknowledgements}

This work was conducted while participating in the JSPS summer institute for doctoral research and was jointly supported by the National Science Foundation East Asia and Pacific Summer Institute program. 


\section{WILL H. RYAN AND SHIN KUBOTA}

\section{Literature cited}

Atoda, K. 1973. Pedal laceration of the sea anemone Haliplanella luciae. Publications of the Seto Marine Biological Laboratory, 20, 299-313.

Chia, F. S. 1976. Sea anemone reproduction: Pattern and adaptive radiation. In G. O. Mackie (ed.), Coelenterate Biology and Behavior. pp. 261-270. Plenum Press, New York.

Fukui, Y. 1995. Seasonal changes in testicular structure of the sea anemone Haliplanella lineata (Coelenterata: Actiniaria). Invertebrate Reproduction and Development, 27, 197-204.

Hammat, M. L. 1906. Reproduction of Metridium marginatum by fragmental fission. The American Naturalist, 40, 583-591.

Minasian Jr, L. L. 1979. The effect of exogenous factors on morphology and asexual reproduction in laboratory cultures of the intertidal sea anemone, Haliplanella luciae (Verrill) (Anthozoa: Actiniaria) from Delaware. Journal of Experimental Marine Biology and Ecology, 40, 235-246.

Miyawaki, M. (1952). Temperature as a factor influencing upon the fission of the orange-striped sea-anemone, Diadumene Luciae. Journal of the Faculty of Science Hokkaido University, Series VI Zoology, 11, 7780.

Shick, J. M. 1976. Ecological physiology and genetics of the colonizing actinian Haliplanella luciae. In G. O. Mackie (ed.), Coelenterate biology and behavior. pp. 137-146. Plenum Press, New York.

Stephenson, T.A. 1935. The British Sea Anemones, vol. 2. London: Ray Society.

Uchida, T. 1932. Occurance in Japan of Diadumene luciae, a remarkable actinian of rapid dispersal (with plate IV, 1 chart and 4 text-figrures). Journal of the Faculty of Science Hokkaido Imperial University, Series VI: Zoology, 2, 69-82.

Uchida, T. 1936. Influence of the currents upon the distribution of races and frequency of asexual reproduction in actinian, Diadumene luciae. Zoological Magazine, Tokyo 48, 895-906 (in Japanese with English summary)

Received: 25 August 2015

Accepted: 30 October 2015

Published online: 4 March 2016 